702

Cooper, P. D., Wilson, J. N. \& Burt, A. M. (1959). J. gen. Microbiol. 21, 702-720

\title{
The Bulk Growth of Animal Cells in Continuous Suspension Culture
}

\author{
By P. D. COOPER, J. N. WILSON AND AVRIL M. BURT \\ Virus Culture Laboratory, Medical Research Council Laboratories, \\ Carshalton, Surrey
}

SUMMARY: Several methods for growing animal cells in suspension culture were examined, to find the most efficient in terms of cells produced in a given time for the minimum of medium and attention. Continuous medium flow was more efficient than batch-culture, and the preferred system was to add medium to a culture vessel regularly in small doses via a time-switch-controlled solenoid closure at a rate similar to the growth rate; a turbidimetric safety device ensured that cell density did not drop below levels permitting growth. A mixture of galactose or fructose $(6 \mathrm{~g}$./l.) and glucose (2 g./.) allowed better $\mathrm{pH}$ control than glucose alone (6 g./l.). Doubling times of 14-16 hr. were obtained on occasion; the gas-phase oxygen concentration for fastest growth depended on cell density and was frequently less than atmospheric, suggesting that these cells can behave as microaerophils.

Microbiologists depend upon an adequate supply of a growth medium for their microbes, and intact animal cells seem likely to remain essential for in vitro growth of animal viruses for some time. Unfortunately, cell supply often limits the work accomplished, so that a simple and cheap laboratory-scale method for bulk growth of continuous cell lines has some attractions. A similar case can be made for cells required for virus vaccine manufacture.

This paper describes an experimental approach to such a method, based on a continuous flow of medium to a culture of suspended cells. Emphasis has been placed on economy of operation, both in materials and attention, and the method should be capable of expansion to pilot-plant scale or contraction to the needs of a small laboratory; its feasibility has previously been reported briefly (Cooper, Burt \& Wilson, 1958). Some aspects of the growth conditions of the cells are reported, particularly their very rapid growth under optimal conditions with a doubling time of less than $16 \mathrm{hr}$., and the inhibitory effect of oxygen excess which could occur at oxygen concentrations less than that in normal air. The use of these cells for poliovirus bulk growth and assay will be described separately.

\section{METHODS}

General scheme. The object was to overcome the bottle-neck of cell production in stationary cultures as cheaply and simply as possible, and continuous suspension culture seemed the best method. However, some ancillary bottle culture was still needed, and a simplified procedure for this is described. Four methods for suspension culture were tried: batch culture, continuous medium flow ('chemostat'), photo-electrically controlled discontinuous medium flow ('turbidostat'), and a combination of the last two ('chemo-turbidostat'). Their merits are compared below. The apparatus used for the turbidostat 
and the chemostat were similar, and the differences involved are described where appropriate. As emphasized below, reliability was essential; all the components described have proved reliable in almost continuous operation at $37^{\circ}$ for between 9 and 25 months.

The apparatus is shown in Fig. 1; where possible, standard commercial products were used throughout. Pyrex aspirators $(20$ l.) acted as medium reservoirs $(a)$, culture vessel $(b)$ and receiver $(c) ; b$ and $c$ were stirred and gassed continuously. Aspirators $b$ and $c$ were silicone-treated before autoclaving; this lessened but did not prevent the accumulation of some cells at the culture meniscus. Medium was allowed to fall at intervals via a solenoidoperated spring closure $(d)$ (Callow \& Pirt, 1956) controlled by a time-switch ('chemostat') or by a photo-electric device ('turbidostat'). These are described in Figs. 2 and 3. Alternatively, medium was continuously pumped (chemostat) at a rate monitored by a rotameter $(e)$ from $a$ to $b$, which overflowed via the constant-level vent into $c$.

The inset within the dotted line shows alternative flow control to the solenoid and includes the pump $(f)$, which consisted of a rotating ring of rollers pressing the rubber tubing against a pivoted plate kept at a constant pressure by a spring. The pumping rate was governed by the speed of rotation, dimensions of the tubing, spacing between the rollers, tension of the spring and the head of medium, the latter necessitating a Marriotte tube in the reservoir to keep the hydrostatic pressure constant. Wear by the rollers on the tubing was considerable. The Marriotte tubes were not necesary for the turbidostat. A rotameter calibrated in 5-150 ml./min. for air was adequate for $0.2-5 \mathrm{l}$. medium $/ 24 \mathrm{hr}$. Cells grew in $b$ in a shallow layer of medium of constant depth (5-7 cm.), but the depth in $c$ increased as cells plus medium entered. The overflow from $b$ must be removed rapidly, and therefore intermittently, rather than by a continuous siphon, as otherwise cells settled in the pipe. Harvesting $(P)$ and replenishing ports $\left(\mathrm{P}^{\prime}\right)$ were dust-caps made of $37 \times 55 \mathrm{~mm}$. or $60 \times 80 \mathrm{~mm}$. aluminium screw-cap containers (Metal Box Co., London, W. 1) with stainless steel tubes bolted through, and could be thoroughly flamed when open or closed. Where possible all tubing and T-pieces, particularly those passing through bungs, were of stainless steel because of occasional accidental breakage of glass tubes. Outflows from culture vessel and receiver were $\frac{3}{8}$ in. internal diam., other tubing was $\frac{1}{4}$ in. internal diam. All pipelines in contact with medium were of silicone rubber tubing (Esco Rubber Co., Ltd., London, N. 16), and air-lines were of 'drab' white rubber tubing (J. G. Ingram and Co., Ltd., London, E. 9); closure was by screw clips (g) on to tubing protected by cotton-backed adhesive tape. Sampling (X) and inoculating (Y) ports employed $\frac{1}{2}$ oz. bottles (United Glass Bottles Ltd., Leicester Street, London, W.C. 2); the central threaded holder was a Hemmings filter (Hemmings Ltd., Beaumaris, Anglesey) with the centre perforated plate drilled out, and the top portion was an inverted $\frac{1}{2} \mathrm{oz}$. bottle with the bottom removed and a bung inserted. The magnetic stirrer motors (Baird and Tatlock Ltd., Chadwell Heath, Essex) had the cover-plates discarded and speed-adjusting rheostats removed for remote operation to avoid local heating; the stirrers were barrel-shaped, weakly 


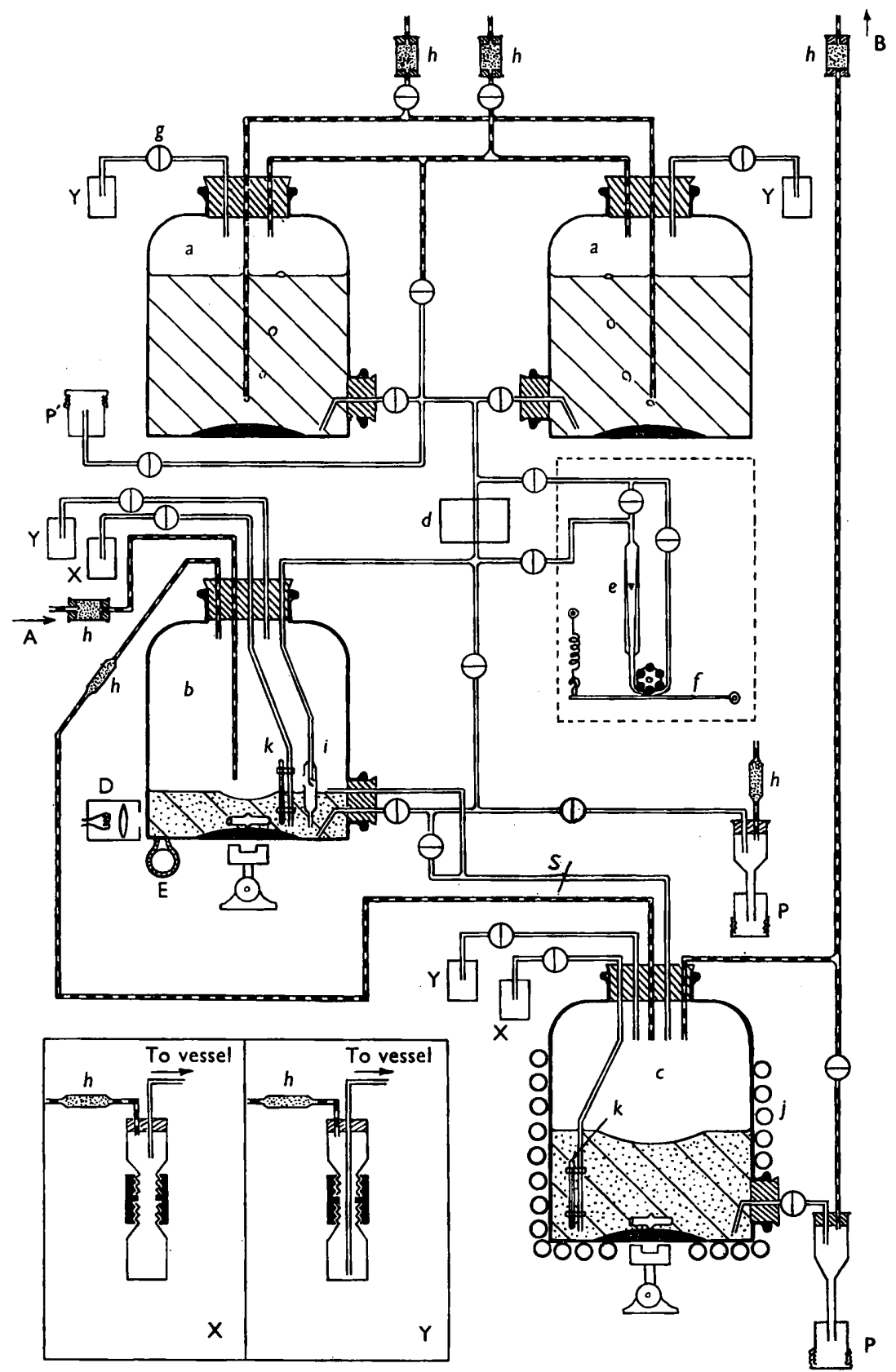

Fig. 1. Assembly of laboratory apparatus used for continuous culture of ERK cells. The lines carrying air or a gas mixture are stippled; $a$, medium reservoirs; $b$, culture vessel ; $c$, receiver; $d$, solenoid valve closure; $e$, rotameter; $f$, pump; $g$, screw clips; $h$, cotton wool plugs; $i$, anti-splash medium inlet; $j$, cooling jacket of rubber tubing; $k$, thermo. meters; A, gas inlet; B, gas outlet; D, light source; $E$, photocell; $P$, harvesting and $P^{\prime}$ replenishing ports. $X$ and $Y$ are sampling and inoculating ports respectively, shown schematically in the main diagram and in detail in the inset; samples were withdrawn via $X$ or added via $Y$ by sucking or blowing through the cotton wool filters. The bar across the medium line at $\mathbf{S}$ indicates the position of the sterile connection made during assembly. 
magnetic stainless steel (Esco Rubber Co., London, N. 16) or strongly magnetic iron covered with polytetrafluorethylene (X-lon Products Ltd., London, S.W. 1). The latter were preferred, but they spin on a central tyre which wore flat in 3 weeks of continuous running; therefore the tyres were machined off and replaced with stainless steel rings. Apart from the sampling, harvesting, replenishing and inoculating ports, all openings to the air were protected by $2 \times 15 \mathrm{~cm}$. cotton-wool plugged tubes $(h)$. To avoid surface bubbles which affected the photoelectric control, the medium inlet had an anti-splash device (i); it was preferred to keep the inlet visible to detect possible leaks through the solenoid closure. The gas outlet $(B)$ was taken to the highest level possible to avoid spillage in case of undue leakage through the solenoid closure. The culture vessel $(b)$ was covered with light-proof black cloth with lift-up flaps for inspecting stirring, volume and temperature. Thermometers $(k)$ enclosed in $b$ and $c$ were tied to the sampling tubes with stainless steel wire so as to be away from the stirrer and more easily visible. The whole device was mounted on a frame in a room at $35^{\circ}-36^{\circ}$ with efficient air circulation; care was necessary to keep heat-producing electrical components away from the culture vessel, in which the temperature was $36^{\circ}-37^{\circ}$. The receiver was cooled to between $28^{\circ}$ and $32^{\circ}$ by water pumped through a jacket of rubber tubing $(j)$ from a water bath (Grant Instruments Ltd., Cambridge), which was cooled by copper coils through which mains water passed and was heated thermostatically to about $27^{\circ}$. A small inverted aspirator filled with water acted as a constantlevel device for the water bath, to replace evaporation losses.

Stirring. Continuous stirring was essential; relatively slow rates were adequate to suspend the cells, but to promote gas exchange a shallow layer with as rapid stirring as possible without frothing was preferred. The culture vessel stirring rate was kept constant at $250-300 \mathrm{rev} . / \mathrm{min}$., using a $6 \mathrm{~cm}$. stirrer, but the receiver stirring rate was increased as the depth of fluid increased. Extensive cell trauma was not found, and grinding was minimized by using a barrel-shaped or centre-tyred stirrer on the convex aspirator bottom; culture volumes of 1-2 1 . rather than $100-200 \mathrm{ml}$. also minimized grinding, loss of cells on meniscus and difficulties of obtaining very low pumping rates. Even with such a shallow layer there was evidence that $\mathrm{CO}_{2}$ removal was not adequate; this could probably be met by higher gas flow rates.

Aeration. A mixture of $\mathrm{O}_{2}, \mathrm{~N}_{2}$ and $\mathrm{CO}_{2}$ was obtained from cylinders with 'BOR 12' (British Oxygen Gases, Greenwich) regulators, which were sufficiently sensitive to control flow rate using a mercury manometer with fine capillary by-pass. The mixture, at a total flow of $100 \mathrm{ml} . / \mathrm{min}$. and monitored by a rotameter as a check on the manometers, was fed without deliberate moistening via a cotton-wool plug (Fig. 1, A) to $3 \mathrm{~cm}$. above the culture surface; the oxygen demand of the culture would probably be met by $10 \mathrm{ml} / \mathrm{min}$. Bubbling gas through the culture in the presence of antifoam agents was avoided because of risk to cell viability; varying the gas mixture could probably meet most oxygen needs.

Medium flow control. Flow in the chemostat was controlled by varying the speed of the pump or altering the duration or frequency of energizing the 
solenoid by the time switch; the difficulties in judging the culture's needs are discussed below. The flow in the turbidostat depended on changes in the light reflected by the culture which increased with increase in cells; an increase in reflected light decreased the resistance of the photocell beneath the culture vessel, and the relay operating the solenoid was actuated when the resistance fell below a pre-set value. The optical arrangement is shown in Figs. 1 and 2; two ORP. 90 cadmium sulphide photocells (Mullards Ltd., London, W.C. 1) were used to minimize effects of variation in light source intensity, resulting particularly from mains voltage variation, which had an appreciable effect on the light even with a constant-voltage transformer (Advance Components Ltd., Ilford, Essex). The light source was an intense light microscope lamp (C. Baker and Co., Croydon, Surrey) with a 6 V.50 W. bulb with five filaments,

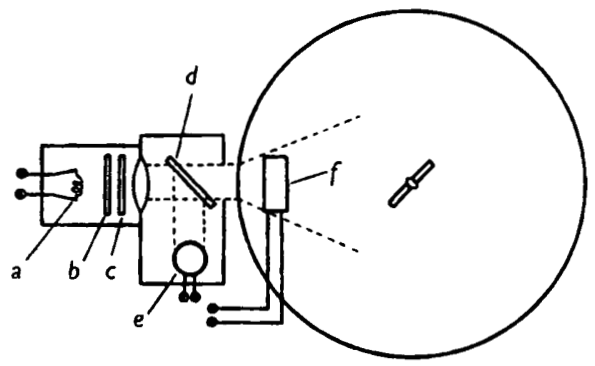

Fig. 2. Plan of optical arrangement for turbidimetric control; the large circle represents the culture vessel and the central bar the stirrer. Light from the bulb $(a)$ passes through heat-resistant $(b)$ and red $(c)$ filters and a focusing lens. Some light is reflected by a sheet of plain glass $(d)$ on to the balancing photocell $(e)$, and the remainder passes into the culture over the controlling photocell $(f)$.

so that failure of one filament would not inactivate the control, and was run at $75 \%$ of rated voltage to increase filament life. As shown in Fig. 2, the light beam entered a light-proof box through a heat-resisting $(b)$ and a red $(c)$ filter (no. OR/2, Pilkington Glass Co., London, S.W. 1) and was partly reflected by a plain glass plate $(d)$ on to the balancing photocell $(e)$; most of the light entered the culture from the side and was reflected by the tissue cells on to the photocell beneath $(f)$. Two alternative electrical control systems were used; one (Fig. 3a) embodied a Multilec controller-recorder (George Kent Ltd., Luton, Beds.) with a knob which could control cell density, coupled to the output of a stable pH meter (Model 23 A, Electronic Instruments Ltd., Richmond, Surrey); the other (Fig. $3 b$ ) used a transistor relay (no. 596 HS (C)/TS. 5205, Magnetic Devices Ltd., Newmarket, Suffolk) across a Wheatstone's bridge, the cell density being varied by the variable resistances. Either system operated the solenoid closure on the medium line via a Sunvic (Sunbury, Middx.) relay no. F. 102/3 M. The first was used to establish the conditions for control from a continuous record, the second was a cheaper alternative suitable for duplication. A third and simpler but less stable circuit (Fig. 3c) was used to control turbidity in the 'chemo-turbidostat' using additionally a time switch (type MZM, Venner Ltd., New Malden, Surrey). An intermittent solenoid closure was 
preferred to a peristaltic pump, as there was much less wear on the tubing and it was easier to buy or build. A forced flow (e.g. by a pump) rather than continuous slow gravity flow was essential, as with such very slow flow rates gas bubbles constantly blocked the medium lines; no such trouble occurred with the rapid intermittent flows from the solenoid valve.

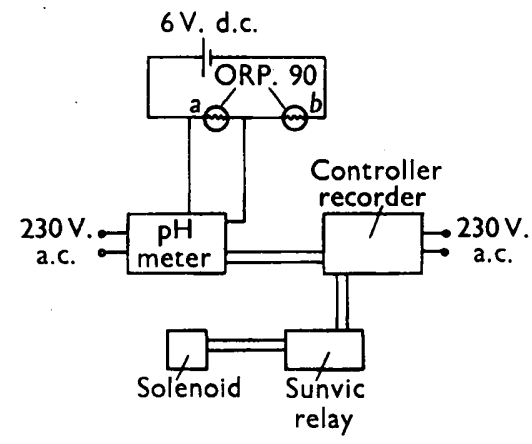

(a)

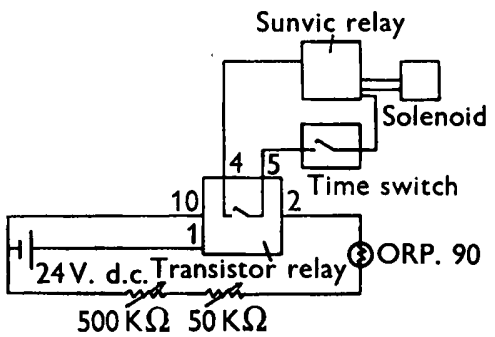

(c)

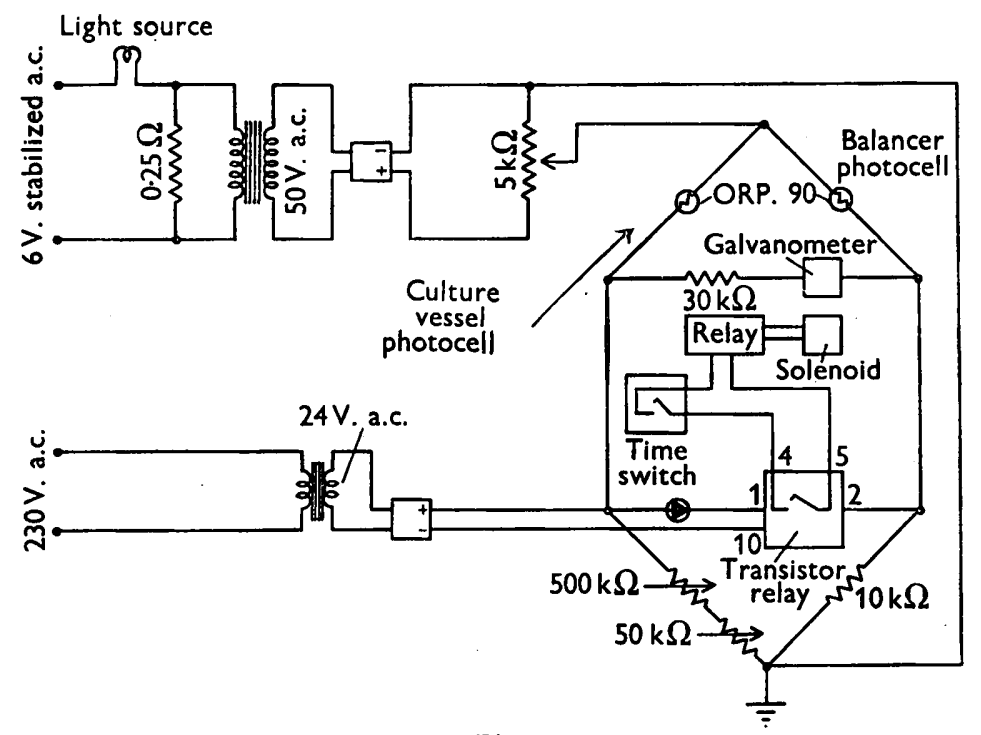

(b)

Fig. 3. Electrical circuits used for the turbidimetric devices. (a) Shows the controller-recorder actuated by the pH meter; of the twin ORP. 90 photocells $a$ is the balancer and $b$ is beneath the culture vessel (see Fig. 2). (b) Is the balanced circuit suitable for independently controlling the turbidostat in which the photocells are arranged as in $(a)$. (c) is the simplified circuit used as a cut-out device for the chemo-turbidostat; the numbers show the connexions for the transistor relay, and the photocell ORP. 90 is placed beneath the culture vessel as in Fig. 1 .

Medium. Advantage was taken of the considerable literature on media for cell culture (e.g. Morgan, 1958). However, most of such work has justifiably aimed at simplification, tending to 'minimal' media, but we have aimed at a 'maximal' medium (medium CSV.6, Table 1) giving fastest growth and highest 
cell densities as cheaply as possible. Earle's saline was used as a basis (Earle et al. 1943) in which the salt concentrations are very similar to those found optimal by Eagle (1956). Lactalbumen hydrolysate $(0.5 \mathrm{mg} . / \mathrm{ml}$.) was roughly equivalent to a 10- to 20-fold Eagle's (1955) amino acid supplement if extra glutamine or glutamic acid plus $\mathrm{NH}_{4} \mathrm{Cl}$ and methionine were added; extra arginine (Thomas, Ziegler, Schepartz \& McLimans, 1958) and inositol were also included together with extra glucose and bicarbonate. The freezing-point of the medium was $-\mathbf{0 . 5 5 ^ { \circ }}$. Most components were added to their highest nontoxic levels; the contents of $\mathrm{K}^{+}$and $\mathrm{PO}_{4}{ }^{\prime \prime \prime}$ should theoretically limit yield to about $2 \times 10^{7}$ cells $/ \mathrm{ml}$., but this level has not been reached (mainly due to difficulties with $\mathrm{pH}$ control and glucose supply); and so no simplification has yet been attempted. Unlike the experience of Ziegler, Davis, Thomas \& McLimans (1958), bicarbonate could not be omitted because of the high acid production by our cells; the other substances with appreciable buffering

Table 1. The components of medium CSV.6

\begin{tabular}{|c|c|c|c|}
\hline & g. $/ 1$. & & g./l. \\
\hline $\mathbf{N a C l}$ & $5 \cdot 48$ & Biotin & $0 \cdot 001$ \\
\hline KCl & 0.5 & Choline chloride & 0.001 \\
\hline $\mathrm{CaCl}_{2}$ & $\mathbf{0} \cdot \mathbf{2}$ & Folic acid & 0.001 \\
\hline $\mathrm{MgCl}_{2} \cdot 6 \mathrm{H}_{2} \mathrm{O}$ & 0.2 & Nicotinamide & 0.001 \\
\hline $\mathrm{NH}_{4} \mathrm{Cl}$ & $0 \cdot 05$ & Calcium pantothenate & $0 \cdot 001$ \\
\hline $\mathrm{NaHCO}_{3}$ & $\mathbf{2 \cdot 5}$ & Pyridoxal 5' phosphate & 0.001 \\
\hline $\mathrm{NaH}_{2} \mathrm{PO}_{4} \cdot 2 \mathrm{H}_{2} \mathrm{O}$ & 0.5 & Thiamine & 0.001 \\
\hline Difco yeast extract & 1.0 & Riboflavine & 0.0001 \\
\hline Lactalbumen hydrolysate & $5 \cdot 0$ & Penicillin & 375,000 units $/ 1$. \\
\hline Glucose & $6 \cdot 0$ & Streptomycin & $0 \cdot 125$ \\
\hline L-Glutamine & $0 \cdot 1$ & Neomycin & $0 \cdot 10$ \\
\hline L-Glutamic acid & $0 \cdot 3$ & Phenol red & 0.01 \\
\hline DL-Methionine & $0 \cdot 1$ & Water & To $1000 \mathrm{ml}$. \\
\hline L-Arginine hydrochloride & $0 \cdot 25$ & Horse serum & $75 \mathrm{ml}$ \\
\hline Inositol & 0.01 & Calf serum & $25 \mathrm{ml}$ \\
\hline
\end{tabular}

The sera were added after making up to 11 .

activity, lactalbumen hydrolysate and phosphate, were at their maximum non-toxic concentration. Although high cell density and ease of operation were the major aims, the growth rates achieved when gas mixtures were optimal were sometimes very rapid. All water was distilled in one step from hard mains water by a glass still (Loughborough Glass Co., Loughborough, Leics.). Horse serum, obtained from selected horses by venepuncture, and calf serum from a local abattoir, were Seitz-filtered without heat-inactivation before being added to the medium, which was then filtered through EK or EKS grade pads (Carlson Ltd., London). With this treatment no pleuropneumonia-like organisms were found in our cultures. Since medium often stood at $37^{\circ}$ for several weeks, the penicillin level is high in CSV. 6; nystatin (Mycostatin, Squibb and Co., Ltd., Speke, Liverpool) was occasionally added sterilely to $25 \mathrm{u}$. $/ \mathrm{ml}$. after filtration but was not added routinely to the reservoirs because of possible accumulation of toxic oxidation products (Paul, 1959); otherwise all mixing was done before filtration. 
Ancillary bottle culture. This has been retained to restart a culture machine with minimum delay in event of breakdown; otherwise cells were stored at $-70^{\circ}$ in $20 \%(\mathrm{v} / \mathrm{v})$ glycerol in horse serum, or as monolayer cultures at $31^{\circ}$ with weekly medium changes, in which case subculture was necessary every 6-8 weeks. Screw-capped bottles (20 oz. medical flats, United Glass Bottles Ltd.), with a culture area of $75 \times 160 \mathrm{~mm}$., were preferred to 11 . Pyrex Roux flasks with bungs for their ease of handling and cheapness; the glass is slightly 'alkaline' but is flatter than the available Pyrex. On average the bottles were used ten times and then rejected. Medium CSV.6 was also satisfactory for stationary bottle culture, giving yields of up to $10^{6} \mathrm{cells} / \mathrm{ml}$. , and a tenfold cell increase per week without medium change if inoculum and initial $\mathrm{pH}$ were correct (see below); use of $0.11 \%$ bicarbonate, $0.1 \%$ glucose and a less alkaline starting $\mathrm{pH}$ gave a faster growth rate (20-fold per week) but required a midweek medium change. Routinely $50 \mathrm{ml}$. of medium were added per bottle (initial $\mathrm{pH} 6.7$, equilibrating without gassing to $\mathrm{pH} 7 \cdot 4$ ) followed by $4 \pm 0.2 \times 10^{6}$ cells, and the bottles were left at $37^{\circ}$ for 7 days before harvesting with $2.5 \mathrm{mg}$. trypsin/ml. (Difco) in phosphate-buffered saline (Dulbecco \& Vogt, 1954). Two separate lines were maintained, and some bottles were placed at $31^{\circ}$ without subculture in case of loss by contamination. Yield was $2-5 \times 10^{7}$ cells/bottle. Bottles when empty were autoclaved in $2 \%(\mathrm{v} / \mathrm{v})$ saturated solutions of sodium hexametaphosphate and sodium metasilicate in tap water, mechanically brushed with brushes made specially for these bottles (Matburn and Co. Ltd., London, W.C. 1), rinsed inside and out with cold tap water, $\mathrm{N}-\mathrm{HCl}$, tap water again and finally four changes of distilled water before dripdrying. Care was taken to prevent drying before the final stage. It is believed that this is one of the simplest effective procedures; the alkaline treatment in time caused a 'bloom' on the glass which hindered cell growth and caused bottles to be rejected. Individual 'toxic' or 'greasy' bottles were rejected forthwith; routine rejection of a cheap bottle was preferred to varying the washing procedure.

Operation of culture machine. The entire apparatus was autoclaved containing a few ml. of water for $1 \frac{1}{2} \mathrm{hr}$. at $10 \mathrm{lb}$. in..$^{-2}$ in two parts, then mounted on its stand and the sterile connexion made (Fig. 1, S). Medium (20-40 l.) was pumped through a sterile filter-press via a sterile connexion (comprising an aluminium dust cap, Fig. 1, $\mathbf{P}^{\prime}$, fitted inside with a short length of silicone tubing) into the reservoirs, and enough medium was run into the culture vessel to overflow. Four to six $20 \times 20 \mathrm{~cm}$. Carlson filter pads (EKS grade) were used and were pre-washed with $8 \mathrm{l}$. distilled water and $1 \mathrm{l}$. of medium; finer grades than this sometimes gave media yielding low growth rates. When filtration was finished, in order to avoid a liquid bridge the medium in the inlet line was drained out before disconnecting the filter press by opening the screw clip leading to the reservoir air-space. The stirring speed was increased almost to frothing, and the gas mixture started at $10 \% \mathrm{CO}_{2}$ and $15 \% \mathrm{O}_{2}$ and left overnight to equilibrate. The cells trypsinized from 20-40 bottle cultures were added next day to give $4-6 \times 10^{5} \mathrm{cells} / \mathrm{ml}$. in the culture vessel, and were followed by mycostatin to give $25 \mathrm{u}$./ $/ \mathrm{ml}$. The $\mathrm{pH}$ was controlled by 
varying the $\mathrm{CO}_{2}$ content of the gas phase. Cell concentrations were determined by haemocytometer count on four replicate samples of 30-200 cells each in the presence of $2 \mathrm{mg}$. trypan blue/ml., blue-staining cells being classed as non-viable. With the chemostat, the cell count and the $\mathrm{pH}$ (as described below) were followed on a daily sample, and the gas and medium flow rates were adjusted daily to maintain optimum conditions; gas bubbles had to be dislodged from the pipelines. The turbidostat and chemoturbidostat, once set at optimal growth rate and cell density, needed a daily check on volume through-put and operation of components and a less frequent cell and $\mathrm{pH}$ check; cells in the receiver were fed twice-weekly with 1-21. medium. The $\mathrm{pH}$ was affected by both $\mathrm{CO}_{2}$ and $\mathrm{O}_{2}$ levels in the gas phase as well as by growth rate and cell density. Cells were harvested once-weekly from the receiver via the lowest port, and in order to avoid a liquid bridge the medium in the lower part of the port was drained out by opening the screw clip leading to the gas outlet. Occasional difficulty was found with the gradual formation of very large clumps which did not overflow from the culture vessel; these were siphoned off when necessary.

Cell strain. A transformed line of embryo rabbit kidney (ERK) cells was used. This was isolated by Westwood, Macpherson \& Titmuss (1957) and grew well in medium CSV.6 after one or two subcultures in this medium in our laboratory.

Cell state. The microscopical appearance of the cells was a useful indication of culture conditions. Oxygen lack or low pH led to a granular cytoplasm and irregular outlines with a tendency to form syncytia; slight oxygen excess gave large clear well-defined cells, becoming very large in dangerous oxygen excess. Trypan blue staining was a good qualitative indication of cell viability (quantitative correlations were not made), but cells generally became trypan bluepositive only when it was too late to remedy the damage. A disadvantage was that the cells often grew in clumps; on a few occasions these became very large (c. $1 \mathrm{~mm}$. diameter).

\section{RESULTS}

\section{Batch growth of ERK cells in stirred suspensions}

Many reports now describe growth of animal cells in suspension, and this was readily confirmed by us (Fig. 4) using a simple stirred pot gassed with $5 \%$ $(\mathrm{v} / \mathrm{v}) \mathrm{CO}_{2}$ in air. These experiments showed that the cells grew rapidly on occasion but growth rate fell markedly above $c .2 \times 10^{6} \mathrm{cells} / \mathrm{ml}$., and the maximum density obtained was $5 \times 10^{6}$ cells $/ \mathrm{ml}$. This limiting density depended on the surface area for a given volume of medium. Addition of glucose and arginine plus inositol (McLimans, personal communication) or a medium change sometimes but not always restored growth. Cell growth rarely started well below $2 \times 10^{5} \mathrm{cells} / \mathrm{ml}$. It was therefore clear that the optimum growth range for animal cells was narrow and was rapidly exceeded in culture, and unless good conditions were rapidly restored the cells entered a lag which was usually long or irreversible. Cell viability was very variable. Such growth also re- 
quired daily attention if good yields were desired, and it was felt that a continuous culture, run under steady optimum conditions, would be more satisfactory. The following section describes attempts to obtain this steady state by adding medium at a constant rate ('chemostat').

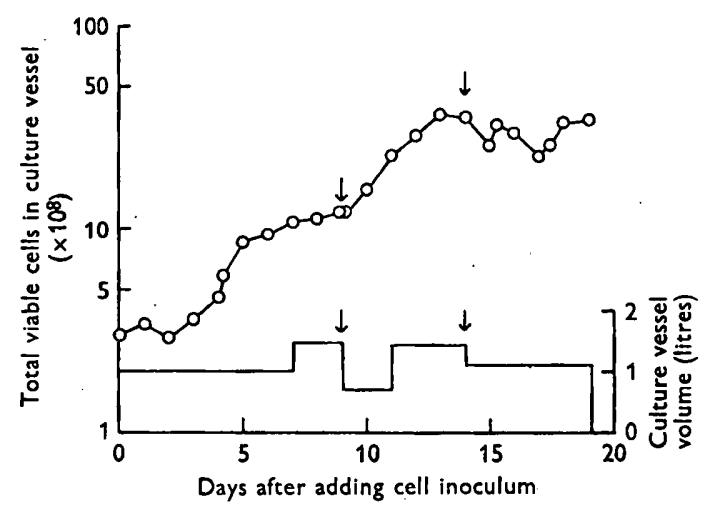

Fig. 4. Rate of growth of ERK cells in batch suspension culture. Changes in volume indicate supplements of fresh medium or complete medium changes (arrows).

\section{Growth of ERK cells in suspension with continuous medium} flow ('chemostat' principle)

Fig. $5 a$ shows the results of the longest of several runs in which growth was continuously maintained by uninterrupted medium flow. Herbert, Elsworth \& Telling (1956) have shown that this type of system with bacteria is much more efficient than batch culture; this seems to apply also to animal cells. Over a period of 4 months, a culture-vessel volume of 1.51 . yielded an average of $10^{9}$ cells per day in 11 . of medium; this was a concentration rarely reached in bottle cultures with the same medium and a rate of yield not obtained in batch suspension culture. The maximum cell density was $2 \times 10^{6}$ cells $/ \mathrm{ml}$.; cell viability was $90-95 \%$. The growth rate was also high, as the doubling time averaged $25 \mathrm{hr}$. over the whole period and was occasionally less than $16 \mathrm{hr}$. Figure 6 shows that when cells were removed from the culture vessel and chilled, growth recommenced almost synchronously with a very short doubling time (14 hr.) if conditions were optimal. Most suspension cultures probably started synchronously, presumably because the cells cool during harvesting.

Unfortunately, although continuous medium flow was more efficient than batch growth, it was more troublesome to operate because the system was not self-balancing and not, therefore, a true chemostat although set up on the chemostat principle. As with bacteria, the cells were washed out of the culture vessel if a constant flow rate exceeded the growth rate; if the growth rate exceeded the flow rate, however, the cell concentration increased to a limiting value (usually with a very low $\mathrm{pH}$ ) and the cells then entered a lag (i.e. growth was not restored by immediately restoring conditions to optimal values) so that the flow rate became excessive and the cells were rapidly 


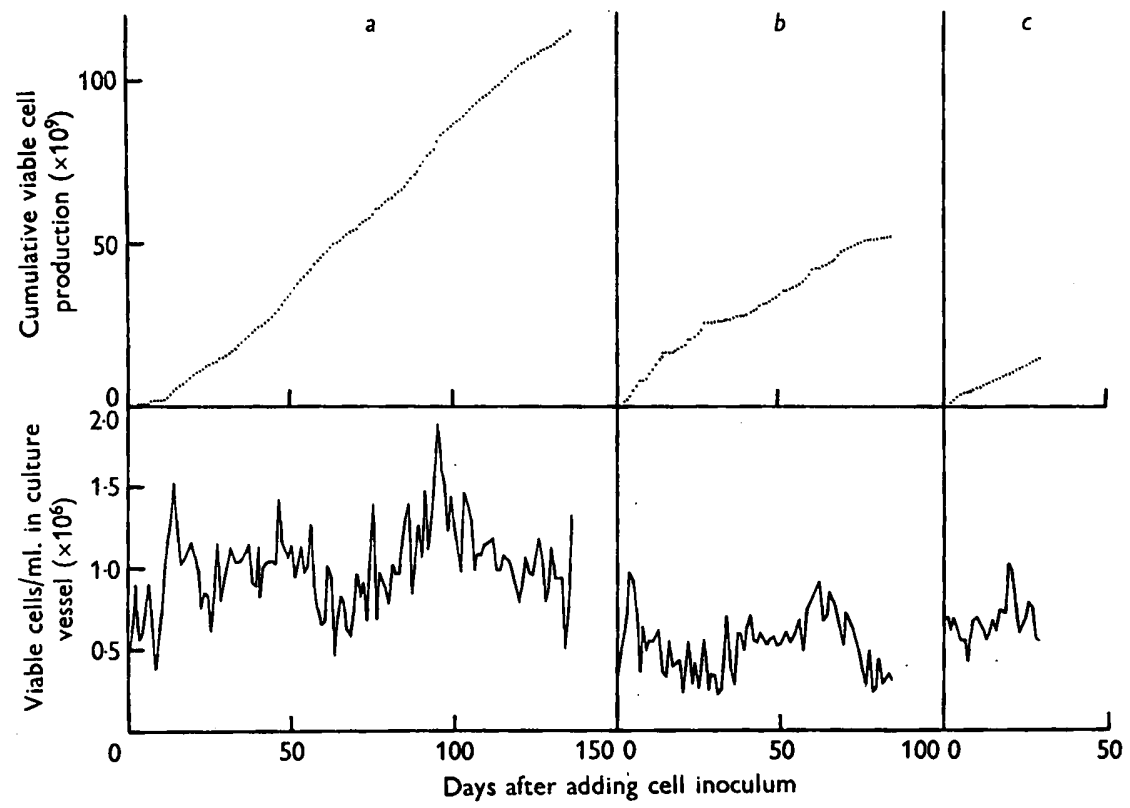

Fig. 5. A comparison of the yields and culture-vessel contents in continuous suspension culture of ERK cells during: $a$, a typical chemostat run; $b$, a typical turbidostat run; and $c$, a typical chemoturbidostat run.

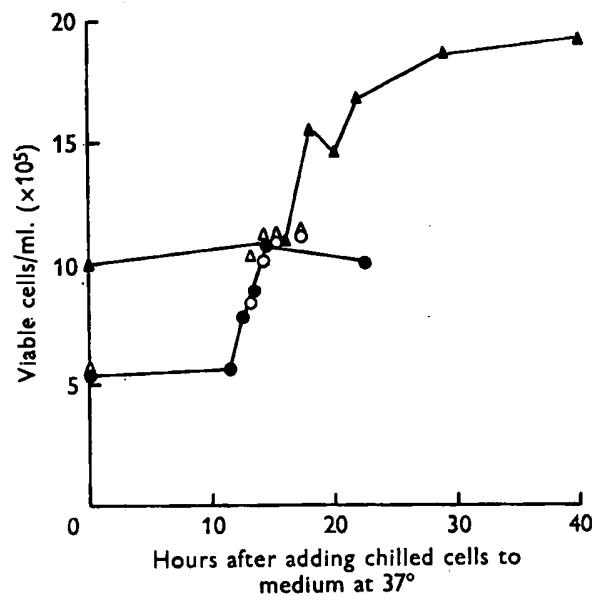

Fig. 6. Synchronous growth from cells adapted to grow in suspension. Cells from the culture vessel during the run shown in Fig. $5(a)$ were centrifuged, shaken gently at $0^{\circ}$ for $1.5 \mathrm{hr}$. and diluted in $100 \mathrm{ml}$. medium CSV.6 at $37^{\circ}$ in a stirred and gassed culture vessel. Gas mixtures (v/v) were $9 \% \mathrm{O}_{2}, 5 \% \mathrm{CO}_{2}$ and $86 \% \mathrm{~N}_{2}$ (Expts. $O, \triangle, 0$ ) or $12 \% \mathrm{O}_{2}, 5 \% \mathrm{CO}_{2}$ and $83 \% \mathrm{~N}_{2}(\Delta)$. 


\section{Animal cells in continuous suspension culture}

washed right out. As mentioned below, oxygen tension in the liquid phase (governed by oxygen tension in the gas phase and cell concentration, other factors being constant) also critically affected growth rate. It is possible that the culture would reach equilibrium if left to itself, but the narrow growth ranges, particularly of cell concentration and $\mathrm{pH}$, make this unlikely; any attempts to allow equilibration were soon terminated as the culture would clearly soon be lost. Therefore, it was necessary every day without exception to anticipate the needs of the culture in the following $24 \mathrm{hr}$., and make adjustments accordingly. On two occasions a steady state was kept for some days, probably because oxygen tension happened to restrict growth rate to the same value as the flow rate.

We therefore conclude that with medium CSV.6 and ERK cells, which do not completely oxidize a large proportion of the available glucose, a culture machine running on the 'chemostat' principle is not a very satisfactory system. The main reason for this is probably that the cells can use glucose at a very high rate whether they grow or not, and glucose restriction does not much restrict growth without harming the cells. Other factors may contribute, however, particularly the difficulty of maintaining cell concentration, oxygen tension and $\mathrm{pH}$ in their narrow optimal ranges. Possibly a differently balanced medium or a rate-limiting component can be found which when deficient will slow growth without damaging the cells; meanwhile, a better self-regulating system was desired, and the approaches to this are described in the following section.

\section{Growth of ERK cells in suspension with automatically controlled medium flow}

Three methods of automatically controlling medium flow seemed feasible, based on $(a)$ redox potential, $(b) \mathrm{pH},(c)$ cell density.

Redox potential. Since growth rate depended on oxygen tension, growth should always be optimal if the oxygen tension or redox potential in the culture was poised at the optimal value. Two experiments were therefore conducted with an immersed platinum electrode and an isotonic saline-agar bridge leading to an external saturated $\mathrm{KCl}$-calomel electrode. The e.m.f. of this cell measured with a pH meter was $c .+200 \mathrm{mV}$. with medium only, but was unchanged by the addition of cells, whatever their state of growth. Presumably either the electrode polarized easily, or the high redox potential inside these cells (Cooper, 1959) does not encourage development of the very reducing environment encountered with bacteria (Hewitt, 1950). This method was therefore abandoned for control purposes.

$p H$. It proved feasible, using a demountable glass electrode (no. GSE. 23, Electronic Industries Ltd., Richmond, Surrey) to mount a glass electrode, with an internal platinum electrode but without the internal buffer solution, inside the culture vessel before autoclaving. After autoclaving the entire apparatus and allowing it to cool, the internal buffer solution was passed via a very fine silicone rubber tube, previously inserted, into the inside of the glass electrode. Using the same agar bridge as before, the system was calibrated 
for $\mathrm{pH}$ by measuring the e.m.f. of the glass-calomel pair when the medium in the culture vessel was without cells and in equilibrium with its gas phase (after $24 \mathrm{hr}$. .). A sample of culture-vessel medium was then withdrawn, and while still at $37^{\circ}$ gassed with the gas effluent from the culture vessel in a small non-sterile assembly which contained glass and calomel electrodes, themselves previously calibrated with standard buffer. The $\mathrm{pH}$ meter recording the $\mathrm{pH}$ in the culture vessel was then set to the true $\mathrm{pH}$ as determined on the withdrawn gassed sample.

This method showed that the pH of very recently withdrawn samples before gassing was about $0 \cdot 1 \mathrm{pH}$ unit higher than after gassing, and that visual estimates of $\mathrm{pH}$ from the phenol red indicator and with $\mathrm{pH}$ test-papers (British Drug Houses, Poole) gave agreement within $\mathbf{0 . 2} \mathbf{p H}$. The $\mathrm{pH}$ was routinely determined either with a $\mathrm{pH}$ meter or visually and with test papers on samples, but before opportunity for cooling and $\mathrm{CO}_{2}$ loss had occurred. Cells briefly tolerated $\mathrm{pH}$ ranges of at least $6 \cdot 6$ to $7 \cdot 4$, but did not grow well unless within $\mathrm{pH} 6 \cdot 9$ to $7 \cdot 1$. This confirms the findings of Kuchler \& Merchant (1956) with growth in suspension; estimation of the true $\mathrm{pH}$ near the cells is difficult in stationary bottle culture, where the $\mathrm{pH}$ in the bulk of the medium is about $\mathrm{pH} \mathrm{7.3}$ for optimal growth. Use of the controller-recorder showed that a small alteration in the $\mathrm{CO}_{2}$ content of the gassing mixture caused a detectable $\mathrm{pH}$ change in a few minutes, but the new $\mathrm{pH}$ value was not established fully for about $6 \mathrm{hr}$; t the half time was about $1 \mathrm{hr}$.

Once calibrated, the internal electrode accurately reflected changes in $\mathrm{pH}$ of the culture for several weeks at least. However, for simple measurement of $\mathrm{pH}$ this method had several disadvantages; $(a)$ re-calibration was lengthy and was necessary 2 or 3 times a week; $(b)$ initial assembly was difficult, particularly in obtaining satisfactory agar-bridges, since it was felt necessary to keep the saturated $\mathrm{KCl}$ from immediate contact with the culture; $(c)$ breakage rate of glass electrodes was high; $(d)$ while one electrode ran for $1600 \mathrm{hr}$. without trouble in the hands of Callow \& Pirt (1956), others were less satisfactory. Since, as mentioned below, long runs are essential for our purpose (preferably $>1600 \mathrm{hr}$.) it is essential that any control system either be very reliable, or be external for replacement without stopping the culture. Its disadvantage as a control system was that maintaining the $\mathrm{pH}$ at 7 units was not by itself sufficient to promote rapid growth; this coupled with difficulty of operation led to our abandoning the immersed glass electrode both for $\mathrm{pH}$ estimation and growth control.

Cell density. Photo-electric control of the turbidity of a cell suspension (turbidostat) works well for bacteria (Bryson, 1952), and a similar system was accordingly applied to the apparatus described in Fig. 1. The principle is that an increase in cell density caused by growth increases the turbidity of the culture above a pre-set value and this automatically causes fresh medium to flow into the culture. The cells are thereby diluted until another pre-set turbidity value is reached, when the medium flow is automatically switched off again. Small mains voltage variations gave large variations in light intensity, and failure of the bulb or lighting circuit inactivated the control, or left the 
solenoid valve open so that medium flowed unrestrictedly; these difficulties were met or minimized by a double-photocell system, a multifilament bulb and the circuits shown in Fig. 3. Some cells settled on the glass over the photocell, but these were removed when necessary by scraping with the magnetic stirrer moved by a magnet held in the hand.

Two machines ran for $\mathbf{8 0}$ and $\mathbf{8 5}$ days respectively as turbidostats and the total cell production is shown for one (Fig. $5 b$ ). As may be expected, culture vessel contents were more stable than in the chemostat but the control was affected by non-viable cells, size of cells, and the turbidity which forms with stirring in absence of cells. Cell viability was $80-90 \%$, in general somewhat less than with the chemostat. When conditions were optimal the growth was quite rapid, but the cultures recovered from periods of suboptimal conditions with difficulty and the cell density tended to drift to low values.

This revealed one fundamental disadvantage of the turbidostat as a system for culturing micro-organisms; unlike the chemostat, it has no intrinsic 'incentive to growth', and relies entirely upon one addition of medium producing sufficient growth to stimulate a second addition. The cell concentrations desired were close to the maximum supported by the medium, and these cells can use much glucose and possibly other substrates without necessarily. growing; if in lag or suboptimal conditions, or in high cell density, they may not grow sufficiently to stimulate the mechanism before their glucose supply is exhausted, and the culture will be lost unless detected in good time and given a supplement of glucose, or a medium change, or deliberately diluted. Thus a pure turbidostat could be used but was not entirely satisfactory; the following section describes a combination of both chemostat and turbidostat principles.

\section{The chemo-turbidostat}

The chemostats in general gave good growth, and their main disadvantage was that literally daily attention was necessary and an error in judging in advance the medium flow rate in relation to cell growth rate sometimes rapidly lowered the cell density below levels permitting growth, or increased it to values at which the cells entered a lag phase. Therefore, several chemostat runs were made in which this snag was met by using the turbidimetric control to stop the supply of medium if the cells were diluted below a certain pre-set minimum. For this, medium was continuously passed in small intermittent doses by means of a time switch actuating the solenoid closure, at a rate if anything slightly greater than the growth rate. The photocell arrangements of Figs. 1 and 2 and the circuits of Fig. $3 b$ or $c$ were used.

Such a system appeared fairly satisfactory, combining 'incentive to growth' with a reliable safety device, and requiring only a rough initial balancing of growth rate and medium input and much less routine attention. Fig. 5c shows a run with this system, additionally using a fructose- or galactose-glucose carbohydrate source. Its cell-production rate averaged the same as the turbidostat but was more stable. 


\section{Variation of carbohydrate source}

A difficulty in the continuous running of cell-culture machines with the ERK cell was the large amount of non-volatile acid produced. Eventually the cultures often became too acid for growth even with no $\mathrm{CO}_{2}$ in the gas phase, necessitating a medium change or addition of bicarbonate. It was hoped to avoid this by replacing glucose by galactose (Eagle, Barban, Levy \& Schulze, 1958), but four attempts (two in stationary and two in continuous suspension culture) failed to subculture cells indefinitely in CSV. 6 containing galactose in place of glucose; the cultures died after 10-20 generations. However, fructose alone, or a mixture of galactose or fructose $(6 \mathrm{~g} . / 1$.) and glucose ( $2 \mathrm{~g} . / 1$.) appeared to carry the cultures well with good growth and less production of non-volatile acid.

\section{Receiver conditions}

As it was convenient to harvest the cells only once-weekly, some storage system was needed. Efficient running would entail a depletion of the environment in the culture vessel, so that without attention the cells overflowing and collecting in the receiver may be in poor condition after 7 days. This was found to be so, and was remedied in part by maintaining the receiver at $30^{\circ}$, and supplementing with fresh medium as follows: after harvesting and draining out all cells, 1-2 l. of fresh medium were run into the receiver from the reservoir as an initial feed, followed by 1-2 l. on the third day and a further 1-2 l. on the sixth day, the cycle being completed by harvesting on the seventh. Viability was then about the same as in the culture vessel. This method, however, is not entirely satisfactory and there is evidence that the cells obtained are not in as good condition as rapidly growing ones; this aspect therefore requires more study. The cooling was insufficient to stop growth completely so that some additional cells were produced by growth in the receiver; sometimes overall yield was deliberately increased by large feeds and by increasing the receiver temperature, but this expedient was inefficient.

\section{The effect of oxygen tension on grozoth rate}

Fig. $5 a$ shows that the culture vessel content during the chemostat run varied widely from day to day; this was because the growth rate also varied. As may be expected, one factor affecting growth rate was the gas phase oxygen tension; growth was slowed by both oxygen lack and excess, the latter sometimes occurring at concentrations less than atmospheric. On two occasions during nearly steady states (Fig. 7) a small increase in oxygen concentration (from 22 to $24 \%, \mathrm{v} / \mathrm{v}$, at day 37 ) halved the growth rate, and a small decrease (from 19 to $17 \%$ at day 45 ) increased the growth rate by $50 \%$. In other experiments higher concentrations (25-30\%) were rapidly cytocidal.

Presumably the important factor is the $\mathrm{O}_{2}$ concentration in the liquid rather than the gas phase, and this will depend on cell concentration among other factors. Figure 7 gives the relations between growth rate, oxygen concentration and cell concentration during two portions of the chemostat run shown in Fig. $5 a$, and shows that growth rates frequently passed through maxima in a 
cyclic manner. A plot of cell concentration against oxygen tension for the 24 hr. periods during this run when growth rates were maximal (Fig. 8) shows that the two are related, and the extrapolation to zero cell concentration suggests that the optimal oxygen concentration in the liquid phase is equivalent to equilibrium with about $9 \%(\mathrm{v} / \mathrm{v})$ oxygen in the gas phase. This concentration is probably not absolute, however, and may, for example, depend on the catalase content of the serum (Lieberman \& Ove, 1958), but the curve was useful in selecting oxygen tensions for optimal growth at given cell densities. Since the cell concentration varied, the liquid-phase oxygen tension should also vary, and this variation presumably caused the changes in growth rate since other conditions were steady; as growth rate in turn affected cell concentration, it is not surprising that conditions were cyclic.

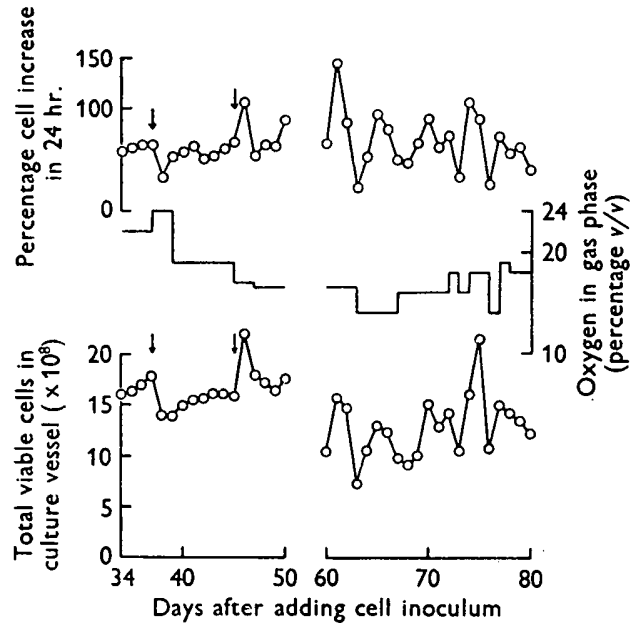

Fig. 7

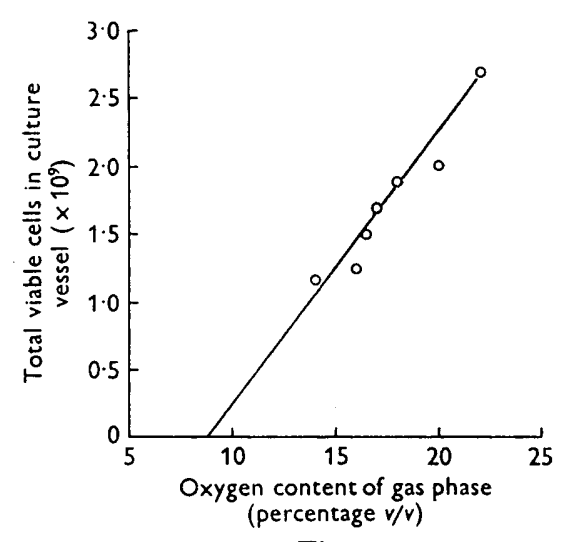

Fig. 8

Fig. 7. Abstracts from the chemostat run of Fig. $5 a$, showing effects of abrupt oxygen gasphase changes during steady state (arrows) and cyclic response of growth rate and culture-vessel content.

Fig. 8. Relation between gas-phase oxygen tension and average culture vessel cell content for all periods when the daily percentage cell increase exceeded $87 \%$ (probable mean doubling times of $\mathbf{2 4} \mathrm{hr}$. or less) during the chemostat run shown in Fig. $5 \mathrm{a}$.

Osgood \& Krippaehne (1955) reported that cells on an inclined immersed microscope slide grow best $1-2 \mathrm{~cm}$. below the surface. Apart from this, the gas phase of tissue cultures has been relatively neglected, but several authors have recently reported that oxygen can be in inhibitory excess at quite low concentrations (Cooper, Burt \& Wilson, 1958; Zwartouw \& Westwood, 1958; Lieberman \& Ove, 1958). Oxygen tensions are also low in tissues in vivo (Davies \& Bronk, 1957). Lieberman \& Ove (1958) state that the oxygen toxicity, particularly marked with single cells, can be overcome with catalase. The inhibitory effect of oxygen may be complex, however, and may perhaps only apply if cells are partly anaerobically adapted; for example, cells in roller tube culture are probably highly aerobic most of the time, yet grow well. 


\section{DISCUSSION}

The term 'continuous culture' is often applied to growth of micro-organisms with continuous medium flow, but is also sometimes applied to batch growth of animal cells when unlimited subculture is achieved. We assume unlimited subculture and use 'continuous culture' for continuous medium flow with suspended cells (chemostat or turbidostat), 'batch-culture' for discontinuous culture of suspended cells and 'bottle-culture' for the necessarily batch growth of monolayers on glass. The terms 'deep' and 'submerged-fermentation' are used in the fermentation industry to distinguish suspended culture from culture on or near the liquid surface; although occasionally used for suspension cultures of animal cells, these terms are avoided here as the distinction does not apply to our system. It should be noted also that for convenience we use the term 'chemostat' for an apparatus set up on the chemostat principle, although in practice it rarely functioned as such.

Several different types of assembly have been used for successful batchculture of suspended animal cells (Graff \& McCarty, 1957; references in Ziegler et al. 1958). In starting the present work we accepted the principle that the simplest system is the stationary 'stirred-pot'. This is general in the fermentation industry; particular advantages are its ease of construction and scaling up or down.

A second principle is that continuous culture can be more efficient and less troublesome than batch-culture (Herbert et al. 1956). We modelled our system where possible on those satisfactory for bacteria (Herbert et al. 1956; Elsworth, Meakin, Pirt \& Capell, 1956), while using ordinary laboratory equipment and allowing for differences in the cells used, animal cells being $(a)$ more easily sedimented, $(b)$ physically more fragile, $(c)$ more sensitive to adverse chemical environment and $(d)$ much slower growing than bacteria. For the last reason, and also because of the complexity of the medium, no theoretical studies were attempted and we assumed that volume change and growth rates at steady state are related as for bacteria (Herbert et al. 1956). As an example of the difficulties of theoretical work, Herbert et al. allowed their bacterial cultures $24 \mathrm{hr}$. to equilibrate after changing conditions slightly; an equivalent time for animal cells would be more than one month.

A third principle is that the apparatus must be reliable in every sense. Where possible, the cheapest and simplest laboratory apparatus has been used, except where apparent simplicity may affect its continuous running. This is because small mechanical failures were often lethal to the cells, and chance contamination has not been countered by any means except dismantling and re-sterilizing, except in two cases where small moulds found growing inside the reservoirs were completely inactivated by adding mycostatin $(500,000 \mathrm{u}$./ 20 1.). Since dismantling, cleaning and re-sterilizing took several days, growth of a fresh inoculum ( $10^{9}$ cells) sometimes took a week, and the cultures once started took 1-2 weeks to reach high yields again, the system was uneconomical unless at least 2 months continuous operation could be expected. However, sources of unreliability were eliminated once found and the components 
described have been quite reliable; the main chance of breakdown lay in contamination during inoculation or replenishing medium in the reservoirs. Harvesting and sampling were adequate with the devices described. Much protection was probably afforded by the antibiotics; however, because of its higher growth rate, once an antibiotic-resistant variant appears the contaminant will be much more likely to take over the culture than in bacterial chemostats (Powell, 1958).

Thus with continuous culture of animal cells, if one needs a large yield one also needs a relatively complex assembly, but a smaller-yielding apparatus could be much more simple. It is likely that the cell needs of a small diagnostic or research laboratory could be met by a small apparatus with a culturevolume of $300 \mathrm{ml}$., a simplified chemo-turbidostat (Fig. $\mathbf{3 c}$ ) and a slow gas supply $\left(10 \mathrm{ml} . / \mathrm{min}\right.$.) from a $5 \%(\mathrm{v} / \mathrm{v}) \mathrm{CO}_{2}$-air cylinder. This should run for several months with little attention, although it seems unlikely that the yieldrate would be optimal. On the other hand, the large cell needs of a commercial plant producing vaccines might well be met by one:10 l. capacity fermentor of a design commercially available. The virus production by these cells will be considered elsewhere, but a single fermentor should be able to match the poliovirus output of most vaccine organizations. if the objection regarding possible malignancy of cells were overcome; this objection may not apply to agricultural animal virus vaccines. A more economical medium than CSV. 6 could almost certainly be found.

In practice, when differences in cell concentrations were allowed for, the yield rates of the three types of assembly described differed by less than twofold, although the actual yield of the chemostat arrangement was greater than the yields of the automatically controlled devices, partly because the attention the former demanded ensured that conditions were more often better and because the latter tended to drift towards lower cell concentrations. Despite this, however, an automatically controlled chemo-turbidostat is much to be preferred for its ease of operation; present work is directed to increasing practical culture-vessel cell populations.

We are indebted to the National Fund for Poliomyelitis Research, by whose generosity the Virus Culture Laboratory was established and this work supported. We are also grateful to Dr F. Sheffield for the original gift of the ERK cells, and to Dr E. Klieneberger-Nobel for testing our cultures at intervals for pleuropneumonialike organisms.

\section{REFERENCES}

Bryson, V. (1952). The turbidostatic selector-a device for automatic isolation of bacterial variants. Science, 116, 48.

Callow, D. S. \& Pirt, S. J. (1956). Automatic control of pH value in cultures of micro-organisms. J. gen. Microbiol. 14, 661.

Cooper, P. D., BURT, A. M. \& Wirson, J. N. (1958). Critical effect of oxygen tension on rate of growth of animal cells in continuous suspended culture. Nature, Lond. 182, 1508.

Cooper, P. D. (1959). Tetrazolium salts as stains for animal virus plaque assays. Virology, 7, 469. 
Davies, P. W. \& Bronk, D. W. (1957). Oxygen tension in mammalian brain. Fed. Proc. 16, 689.

Dulbecco, R. \& Vogt, M. (1954). One step growth curve of western equine encephalomyelitis virus on chick embryo cells grown in vitro and analysis of virus yields from single cells. J. exp. Med. 99, 183.

EagLe, H. (1955). Nutrition needs of mammalian cells in tissue culture. Science, $122,501$.

EAGLE, H. (1956). The salt requirements of mammalian cells in tissue culture. Arch. Biochim. biophys. 61, 356.

Eagle, H., Barban, S., Levy, M. \& Schulze, H. O. (1958). The utilization of carbohydrates by human cell cultures. $J$. biol. Chem. 233, 551 .

Earle, W. R., Schilling, E. L., Stark, T. H., Straus, N. P., Brown, M. F. \& Shelton, E. (1943). Production of malignancy in vitro. IV. The mouse fibroblast cultures and changes seen in living cells. J. nat. Cancer Inst. 4, 165.

Elsworth, R., Meakin, L. R. P., Pirt, S. J. \& Capell, G. H. (1956). A two litre scale continuous culture apparatus for micro-organisms. J. appl. Bact. 19, 264.

Graff, S. \& McCarty, K. S. (1957). Sustained cell culture. Exp. Cell Res. 13, 348.

Herbert, D., Elsworth, R. \& Telling, R. C. (1956). The continuous culture of bacteria; a theoretical and experimental study. J. gen. Microbiol. 14, 601.

Hewrte, L. F. (1950). Oxidation-Reduction Potentials in Bacteriology and Biochemistry. Edinburgh: E. and S. Livingstone Ltd.

Kuchler, R. J. \& Merchant, D. J. (1956). Propagation of strain L (Earle) cells in agitated fluid suspension cultures. Proc. Soc. exp. Biol., N.Y. 92, 803.

Lieberman, I. \& Ove, P. (1958). Catalase requirement for mammalian cells in culture. J. exp. Med. 108, 631.

Morgan, J. F. (1958). Tissue culture nutrition. Bact. Rev. 22, 20.

Osgood, E. E. \& Krippaehne, M. L. (1955). The gradient tissue culture method. Exp. Cell Res. 9, 116.

PaUL, J. (1959). Cell and Tissue culture, p. 108. Edinburgh: E and S. Livingstone Ltd.

Poweld, E. O. (1958). Criteria for the growth of contaminants and mutants in continuous culture. J. gen. Microbiol. 18, 259 .

Thomas, W. J., Ziegler, D. W., Schepartz, S. A. \& Mclimans, W. F. (1958). Use of arginine to eliminate medium changes in tissue culture systems. Science, 127, 591.

Węstwood, J. C. N., MacPherson, I. A. \& Trtmuss, D. H. J. (1957). Transformation of normal cells in tissue culture; its significance relative to malignancy and virus vaccine production. Brit. J. exp. Path. 38, 138.

Ziegler, D. W., Davis, E. V., Thomas, W. J. \& Mclimans, W. F. (1958). The propagation of mammalian cells in a $20 \mathrm{l}$. stainless steel fermentor. Appl. Microbiol. 6, 305.

Zwartouw, H. T. \& Westwood, J. C. N. (1958). Factors affecting growth and glycolysis in tissue culture. Brit. J. exp. Path. 39, 529.

(Received 8 June 1959) 